Research Article

\title{
Wideband Slot Array Antenna Fed by Gap Waveguide with Right-Handed Circular Polarization and High Gain
}

\author{
Pejman Mahmoudi Kanesbi $(\mathbb{D})$ and Nasrin Amiri $(\mathbb{D}$ \\ Department of Electrical and Computer Engineering, South Tehran Branch, Islamic Azad University, Tehran, Iran \\ Correspondence should be addressed to Nasrin Amiri; n_amiri@azad.ac.ir
}

Received 18 May 2021; Revised 4 July 2021; Accepted 8 July 2021; Published 20 July 2021

Academic Editor: Mohammad Alibakhshikenari

Copyright (c) 2021 Pejman Mahmoudi Kanesbi and Nasrin Amiri. This is an open access article distributed under the Creative Commons Attribution License, which permits unrestricted use, distribution, and reproduction in any medium, provided the original work is properly cited.

A wideband and high-gain circularly polarized (CP) $16 \times 16$ array antenna based on gap waveguide technology is presented for millimeter-wave applications at $28 \mathrm{GHz}$ frequency range. Four cavity-backed slots with linear polarized (LP) radiation are used as the subarray. CP is obtained by a $4 \times 4$ sequential feeding network which is also expanded to achieve high gain. The feeding network of the final array antenna consists of two layers based on the ridge gap waveguide (RGW), and it has four unconnected metal layers. It is shown by simulation that the proposed antenna has $20.5 \%$ impedance bandwidth over $25.8-31.7 \mathrm{GHz}$ and $3 \mathrm{~dB}$ axial ratio bandwidth near $10 \%$ over $27.2-30 \mathrm{GHz}$. In addition, the maximum gain value for this antenna is $31.6 \mathrm{dBi}$ at a frequency of $29 \mathrm{GHz}$, which shows good performance compared to other structures.

\section{Introduction}

In recent years, high-frequency and millimeter-wave frequency bands have gained much attention due to the increasing demand for high-rate data transformation. Lowcost and high-gain antennas are required for point-to-point communication in the millimeter-wave frequency range. Furthermore, planar antennas are the most common because of the compact system requirements.

There are different conventional types of the technologies that are used in planar array antennas, such as hollow waveguides, substrate integrated waveguides (SIW), and microstrip lines [1-15]. Although SIW and microstrip lines have low profile and easy manufacturing, they have dielectric losses, especially in the millimeter-wave frequency range [1-7]. In addition, the low-loss dielectrics can be used to reduce the losses, which are expensive and increase the cost of fabrication [16, 17]. Hollow waveguide antennas have low loss and high power-handling capacity in the millimeter-wave frequency band [8-12]. However, they need good electrical contact between metal parts in the structure and require high precision, which is difficult and expensive.
To overcome the aforementioned problems, a new waveguiding technology called gap waveguide has been introduced in $[18,19]$. Gap waveguides can be realized without the need for good electrical contact between the metal layers [20-34]. Therefore, this technology makes the manufacturing process easier and much cheaper than hollow waveguides. The advantages of gap waveguides compared to substrate-based transmission lines, such as SIW and microstrip lines, are that these structures can be realized totally with metal, which makes them have low losses and high power handling. The gap waveguide structure is based on two perfect electrical conductor (PEC) and perfect magnetic conductor (PMC) boundary conditions. The PMC boundary condition acts like a high impedance surface, and it can be realized by using a periodic texture of metal pins called bed of nails. If the gap between two plates is smaller than the quarter of wavelength, then no waves can propagate, and all parallel-plate modes will be in cutoff frequency. By using a ridge, groove, or microstrip line between the bed of nails, the field will propagate in the desired direction. These techniques are known as ridge gap waveguide (RGW) [31], groove gap waveguide (GGW) [32], and microstrip gap waveguide [33], respectively. 
Antennas with circular polarization are widely used in satellite communication in the move (SOTM) and point-topoint moving links due to their resistance to polarization mismatch and multipath effects. Applications of these links require $\mathrm{CP}$ antennas with proper radiation characteristics, such as high gain, broadband bandwidth, and broadband axial ratio (AR) bandwidth. There are also other desirable features such as simple structure, low profile, and low cost for mounting in cars, airplanes, trains, and other moving vehicles. There are two ways to obtain circular polarization in planar array antennas. The first method is to use CP antenna elements in an array. However, it suffers from narrow bandwidth [35-41]. The second method is to employ the antenna element and subarray with a feeding system, which results in circular polarization. The sequential rotation technique (SRT) is a suitable choice to achieve wideband AR where antenna elements are fed by the same magnitude and progressive phase shifts of $90^{\circ}$ [42]. Several studies have proposed that the sequential feeding network is employed in conventional planar array antennas to improve AR bandwidth [43-45]. Recently, a two-level sequential feeding network for an $8 \times 8 \mathrm{CP}$ array antenna is presented, in which the antenna gain reached to $23.5 \mathrm{dBi}$ [20]. In this paper, a 4-way sequential-phase feeding network based on the RGW is proposed. Then, it is expanded to feed a $16 \times 16$ CP array antenna, which achieves the highest gain.

The feeding network of the antenna consists of two layers of 64 subarrays fed with a $2 \times 2$ cavity-backed slot antenna. The geometry of the antenna and the simulation results of the subarray are presented in Section 2. In Section 3, the sequential feeding network for a $4 \times 4 \mathrm{CP}$ array is investigated. The simulation results of the final antenna are presented in Section 4, and finally, the paper is concluded in Section 5 .

\section{2. $2 \times 2$ Cavity-Backed Subarray Design}

Figure 1 shows the schematic diagram of a $2 \times 2$ cavitybacked slot subarray, with linear polarization that is similar to the one which has been used in [24]. It consists of three unconnected metal layers as shown in Figure 1(a). In the radiation layer, each slot is surrounded by a cylindrical cavity to suppress surface waves and mutual coupling between other adjacent slots. As explained in [24], separating $E$ - and $H$-planes of the antenna from the principle plane of the array reduces the sidelobe level of the antenna. Therefore, each slot is tilted by $10^{\circ}$ as shown in Figure 1(b). The cavity layer is formed by the metal pins and feeds four radiation slots in the same phase and amplitude as shown in Figure 1(c). Figure 1(d) depicts the feeding layer of the subarray that is based on RGW technology and the quasi-TEM mode, which is coupled to the cavity layer by a $T$-shaped ridge via a coupling slot. The dispersion diagram of the pin unit cell used in the subarray is shown in Figure 2. It is calculated by CST Eigenmode Solver for a pin unit cell with periodic boundary conditions on two sides. The pin dimensions are chosen to have a stopband with covering working frequency in $28 \mathrm{GHz}$. As can be seen, the stopband of the pin for parallel-plate propagation modes starts from 17 to $48 \mathrm{GHz}$, and it is suitable for using in the subarray structure. The dimensions of the subarray are presented in Table 1. Figure 3 shows the simulated reflection coefficient of the subarray with the periodic boundary condition in CST Microwave Studio. The impedance bandwidth of the subarray is from 25.7 to $30.3 \mathrm{GHz}$.

\section{3. $4 \times 4$ CP Array Design}

Figure 4 shows the configuration of the $4 \times 4 \mathrm{CP}$ array. The structure consists of four $2 \times 2$ subarrays with sequential rotation placement. As shown in Figure 4, the bottom layer is the sequential-phase network with four outputs that is similar to the one in [20]. To achieve a $90^{\circ}$ phase shift between ports 2 and 3, the length difference between $L_{2}$ and $L_{1}$ is chosen as $5 \lambda / 4$, where $\lambda$ is the wavelength of the center frequency of the antenna. The $90^{\circ}$ phase difference between ports 4 and 5 is obtained by the same method. In addition, a $180^{\circ}$ phase delay between two branches of the first power divider is achieved by $L_{L}-l_{R}=\lambda / 2$. The dimensions of the sequential-phase feeding network are optimized by CST Microwave Studio. The simulated reflection and transmission of the sequential feeding network are shown in Figure 5. It is clear that the reflection coefficient from 24 to $35 \mathrm{GHz}$ is below $-27 \mathrm{~dB}$, and the imbalance transmission coefficient of the outputs is less than $0.4 \mathrm{~dB}$ over the entire bandwidth. Figure 6 shows the phase difference of the sequential-phase feeding network. As can be seen, a right-handed $90^{\circ}$ phase shifting between the outputs is evident at $27.7 \mathrm{GHz}$.

Simulated AR and gain of both $2 \times 2$ and $4 \times 4$ subarrays are presented in Figure 7 . The AR magnitude for the $2 \times 2$ subarray is above $20 \mathrm{~dB}$ over the frequency range of $24-33 \mathrm{GHz}$ due to its linear polarization. The $3 \mathrm{~dB} A \mathrm{AR}$ bandwidth of the $4 \times 4$ array is from $27.2 \mathrm{GHz}$ to $30 \mathrm{GHz}$, which indicates that circular radiation has been achieved in this frequency range. The gain of the $2 \times 2$ subarray is below $15 \mathrm{dBi}$. By expanding this subarray to a $4 \times 4$ array, the gain has been increased above $17 \mathrm{dBi}$ with the maximum gain of $19 \mathrm{dBi}$ at $28.7 \mathrm{GHz}$.

\section{4. $16 \times 16$ CP Array Antenna Design}

The 4-way power divider described in the previous section can be expanded as the feeding network of the $16 \times 16 \mathrm{CP}$ array antenna. The schematic diagram of the presented feeding network is illustrated in Figure 8. There is no enough space to place ridge lines and power dividers between 4-way power dividers for a compact integration due to the space limitation. Therefore, the feeding network of the antenna cannot be placed in one single layer, and it is required to add another layer at the bottom of the structure. Subsequently, the final array antenna consists of four layers. Figure 9 shows the two feeding network layers of a $4 \times 8$ array. One sequential feeding network is rotated by $180^{\circ}$, and since the 4 way sequential feeding network is not rotationally symmetric, a phase difference of $180^{\circ}$ occurs between the outputs of the subfeeds at the top and bottom half of the entire feeding network. If identical radiators are connected to the 


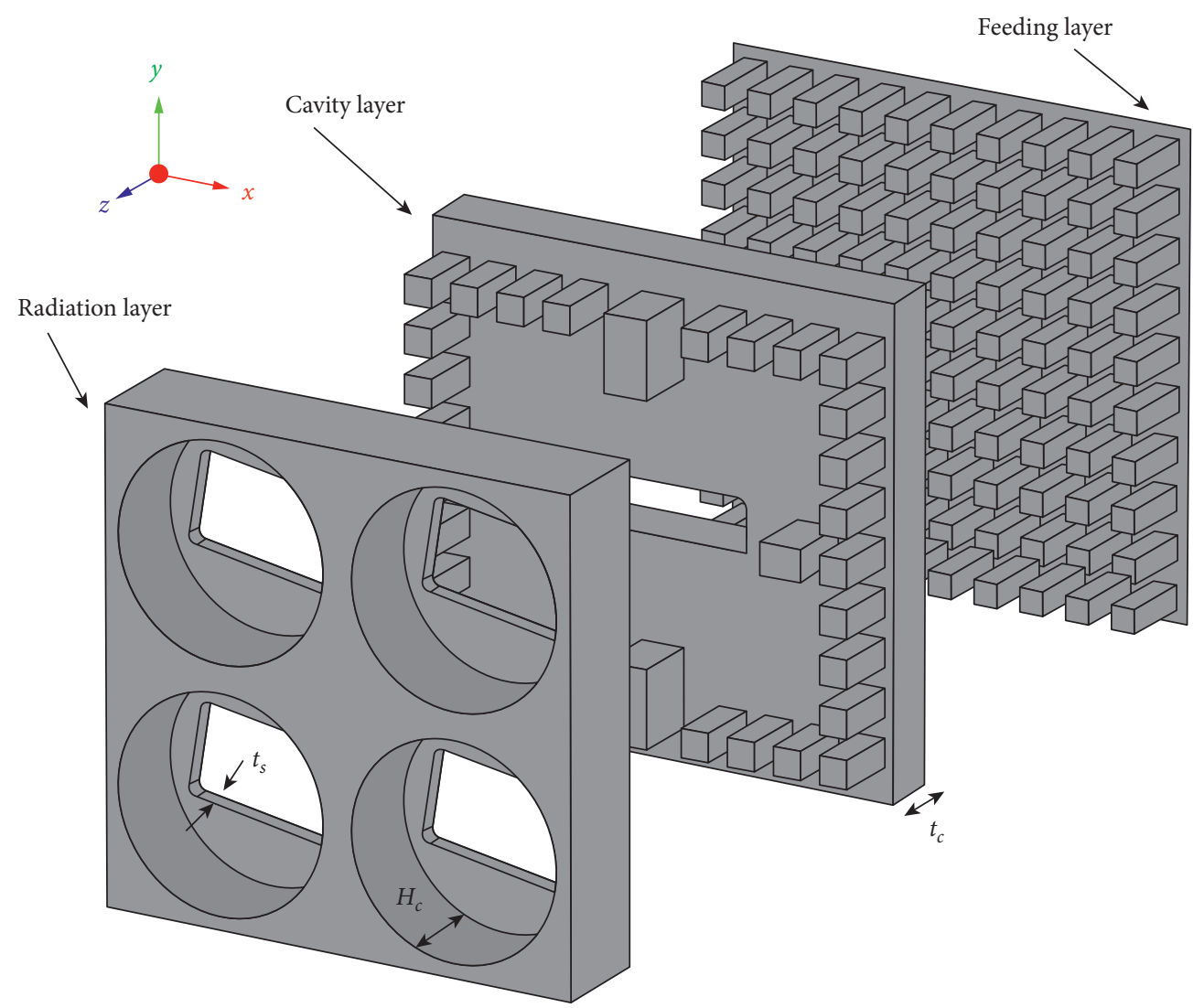

(a)

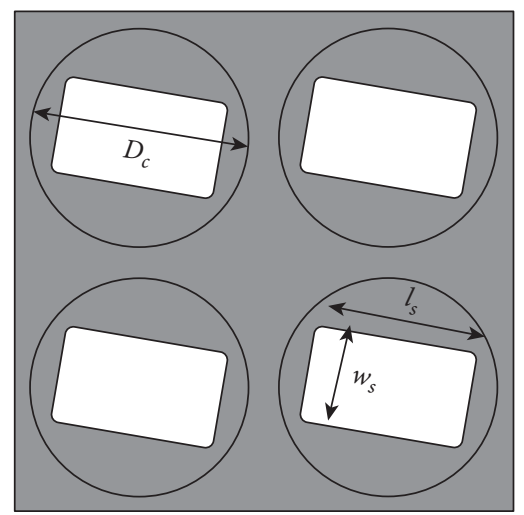

(b)

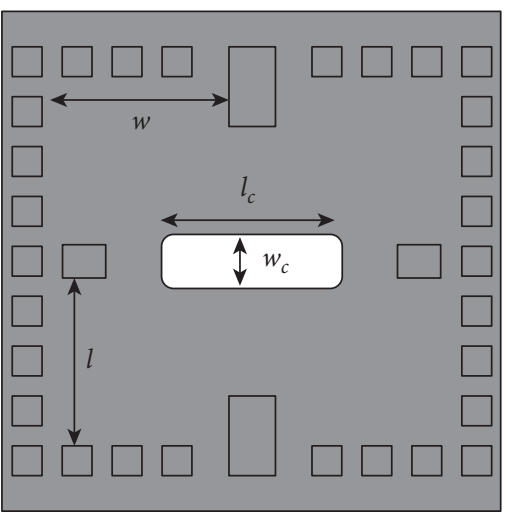

(c)

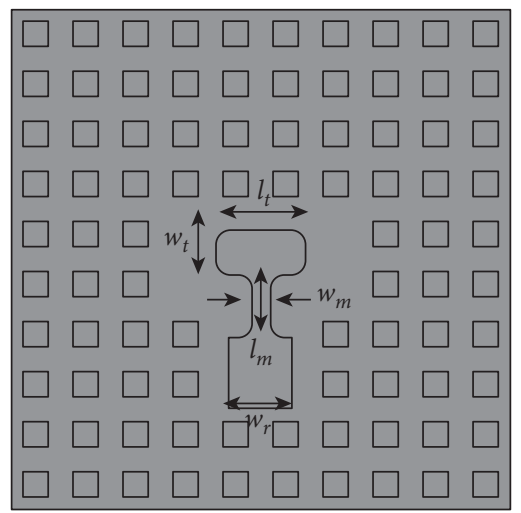

(d)

FIGURE 1: (a) Exploded view of a $2 \times 2$ cavity-backed slot subarray. (b) Radiation layer. (c) Cavity layer. (d) Feeding layer. 


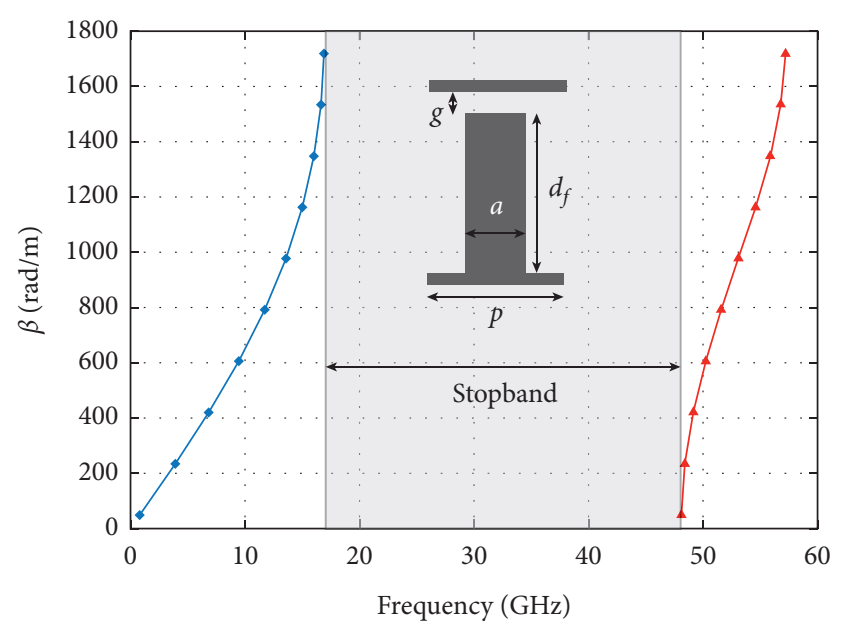

$\longrightarrow$ Mode 2

$\rightarrow$ Mode 1

FIgURE 2: Dispersion diagram for the pin unit cell $(p=1.77 \mathrm{~mm}$, $a=0.89 \mathrm{~mm}, d_{f}=2.88 \mathrm{~mm}$, and $g=0.12 \mathrm{~mm}$ ).

TABLE 1: Dimensions of the $2 \times 2$ cavity-backed slot subarray.

\begin{tabular}{lcc}
\hline Component & Parameter & $\begin{array}{c}\text { Value } \\
(\mathrm{mm})\end{array}$ \\
\hline & $\begin{array}{c}\text { Slot spacing in the } x \text { - and } y \text { - } \\
\text { direction }\end{array}$ & 8.85 \\
Radiation & $H_{c}$ & 3.26 \\
layer & $D_{c}$ & 7.77 \\
& $l_{s}$ & 5.88 \\
$w_{s}$ & 3.46 \\
$t_{s}$ & 0.62 \\
\hline Cavity layer & $w$ & 6 \\
& $l$ & 6.66 \\
& $w_{c}$ & 1.9 \\
& $l_{c}$ & 6.43 \\
& $t_{c}$ & 2.22 \\
\hline & $w_{r}$ & 2.22 \\
Feeding layer & $d_{r}$ & 2.4 \\
& $l_{T}$ & 3.1 \\
& $w_{T}$ & 1.55 \\
& $l_{m}$ & 2.22 \\
$w_{m}$ & 0.67 \\
\hline
\end{tabular}

feeding network, this will lead to a null at the boresight direction.

To overcome this problem, the phase difference must be removed. To achieve this, an E-probe transition is designed between feed- 1 and feed- 2 to match the ridge gap waveguide line in the bottom layer to sequential feeding networks in the top layer. Figure 9 shows the simulated structure of the $E$ probe transition between feed- 1 and feed-2 layers. The dimensions of the transition are shown in Figure 10. As can be seen in Figure 11, the input reflection coefficient of the transition is almost below $-20 \mathrm{~dB}$ over the frequency range of $24-33 \mathrm{GHz}$, and the output reflection coefficient is $-3 \mathrm{~dB}$. The simulated output phase differences of the proposed transition are shown in Figure 12. It can be seen that the

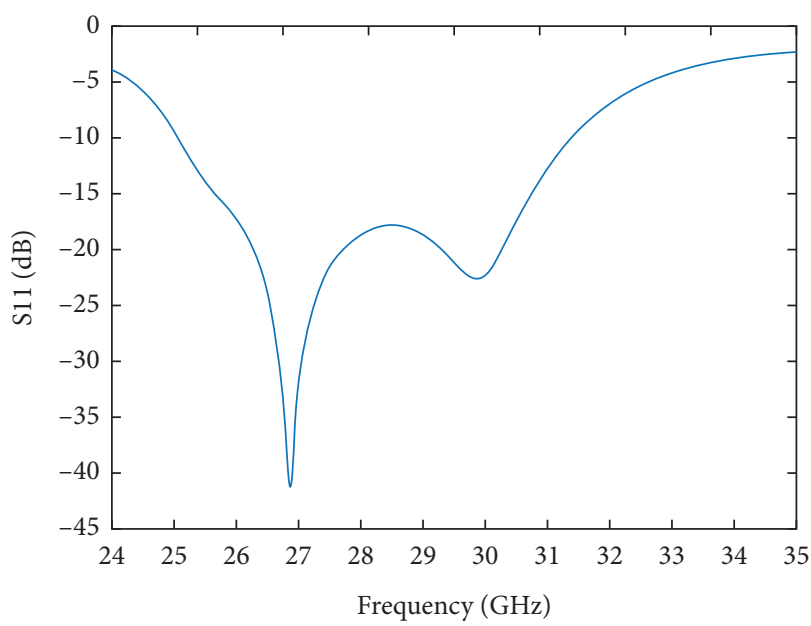

FIGURE 3: Simulated reflection coefficient of the $2 \times 2$ slot subarray.

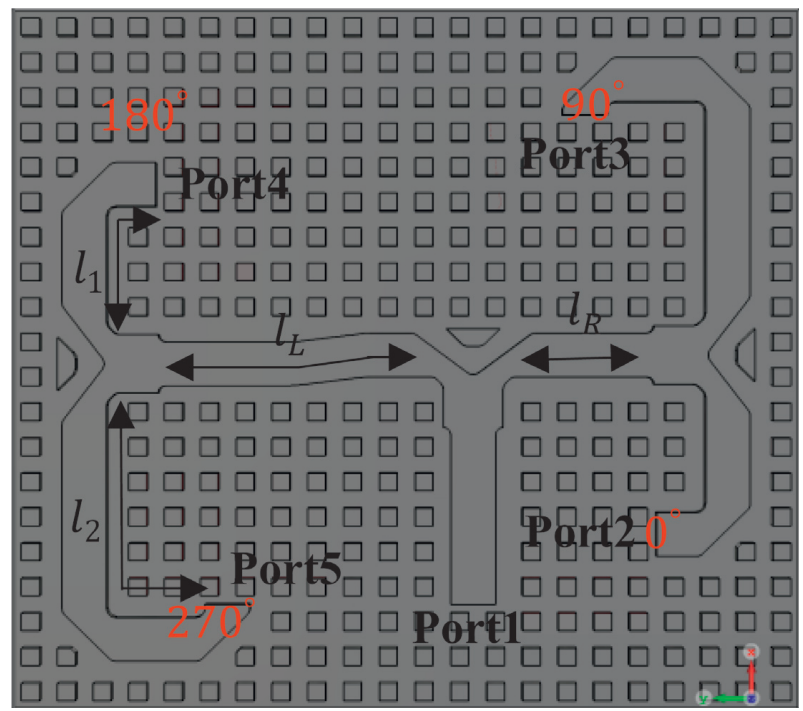

FIgURE 4: The geometry of the 4-way sequential-phase feeding network.

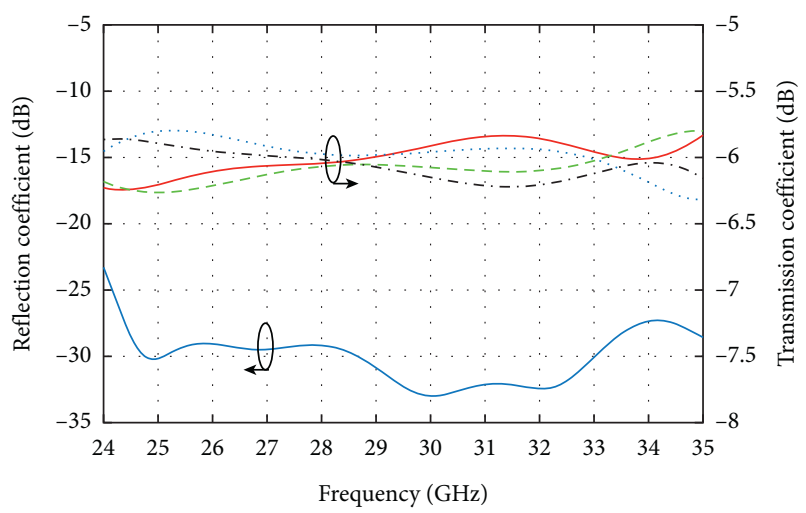

FIGURE 5: Simulated reflection and transmission coefficients of the sequential feeding network. 


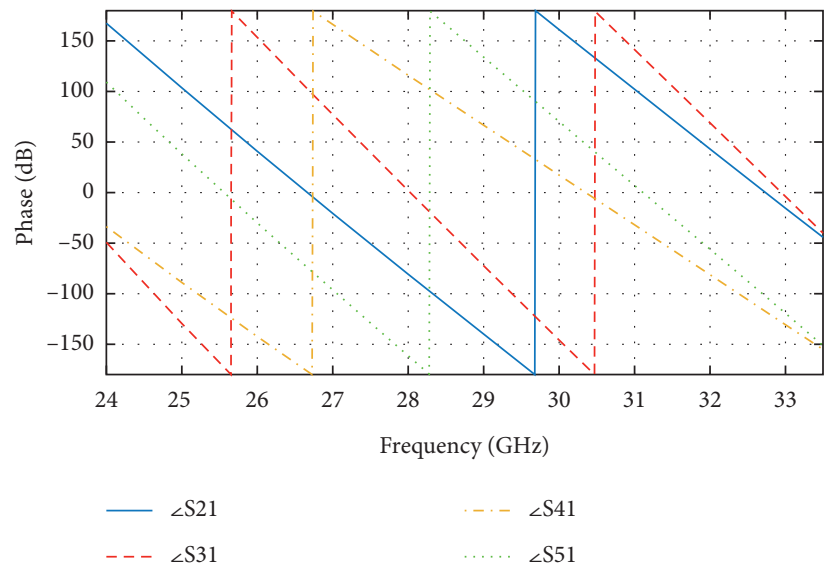

FigURE 6: Simulated phase of the sequential-phase feeding network output ports.

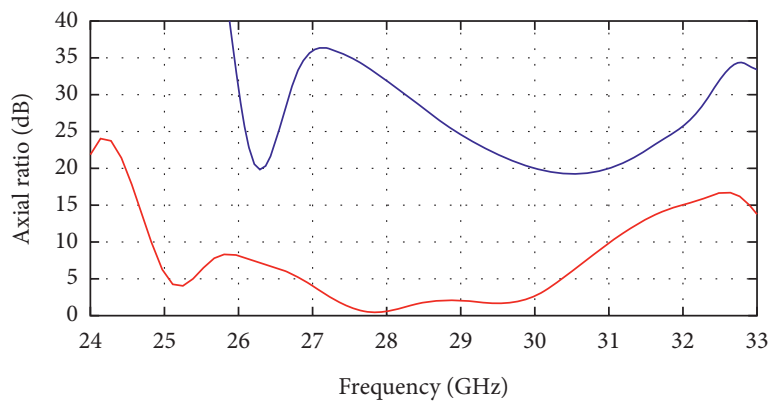

- $4 \times 4$ subarray

$2 \times 2$ subarray

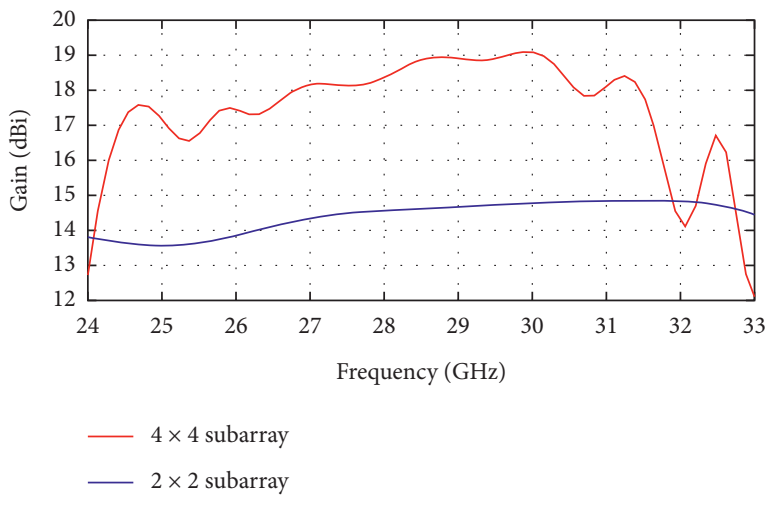

(b)

Figure 7: Simulated (a) AR and (b) gain of $2 \times 2$ and $4 \times 4$ subarrays.

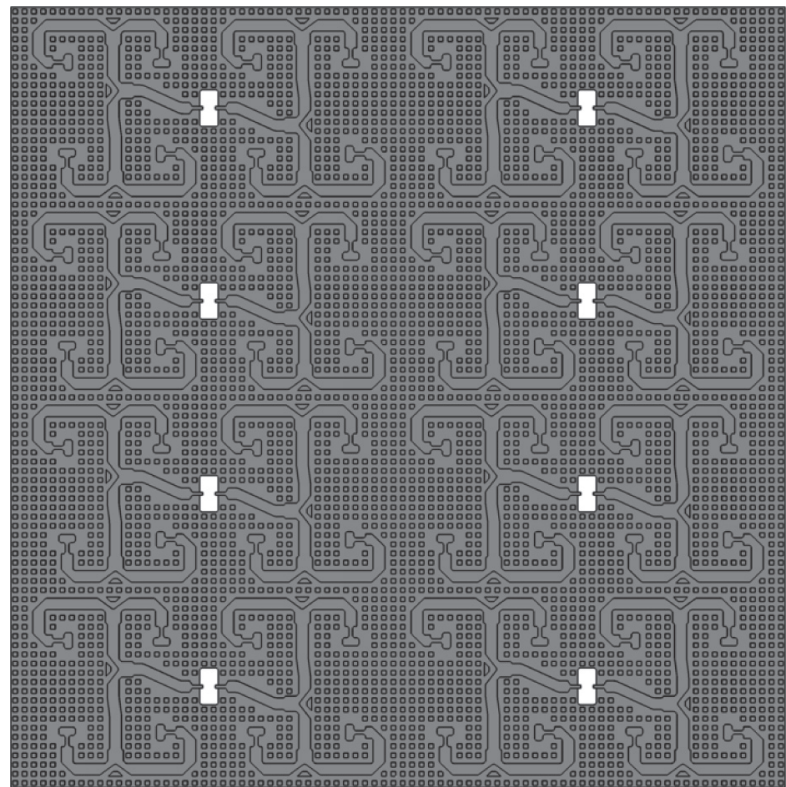

(a)

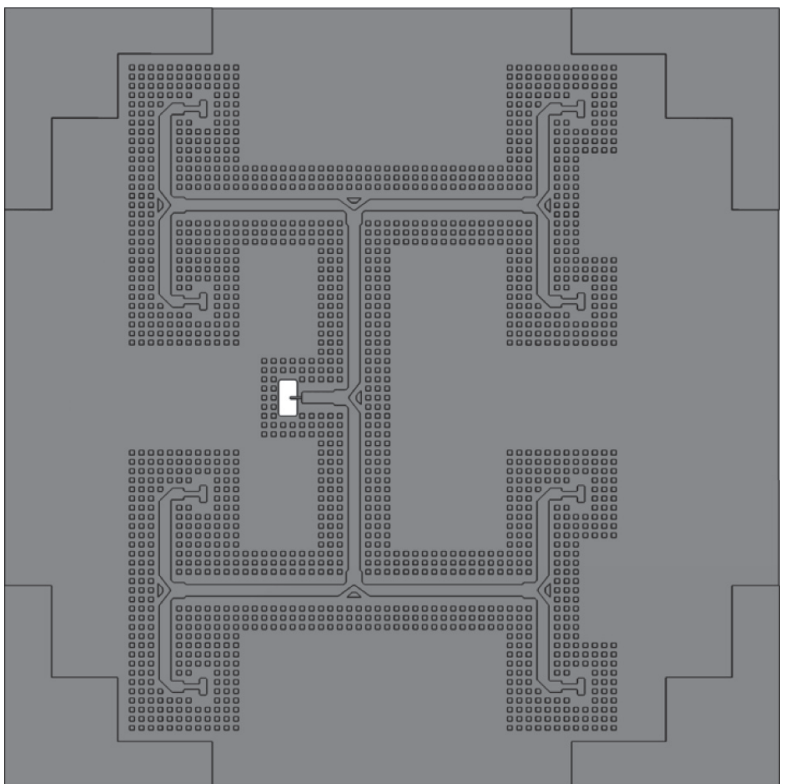

(b)

FIGURE 8: Feeding network of the $16 \times 16 \mathrm{CP}$ array antenna. (a) Feed-1 (top layer). (b) Feed-2 (bottom layer). 


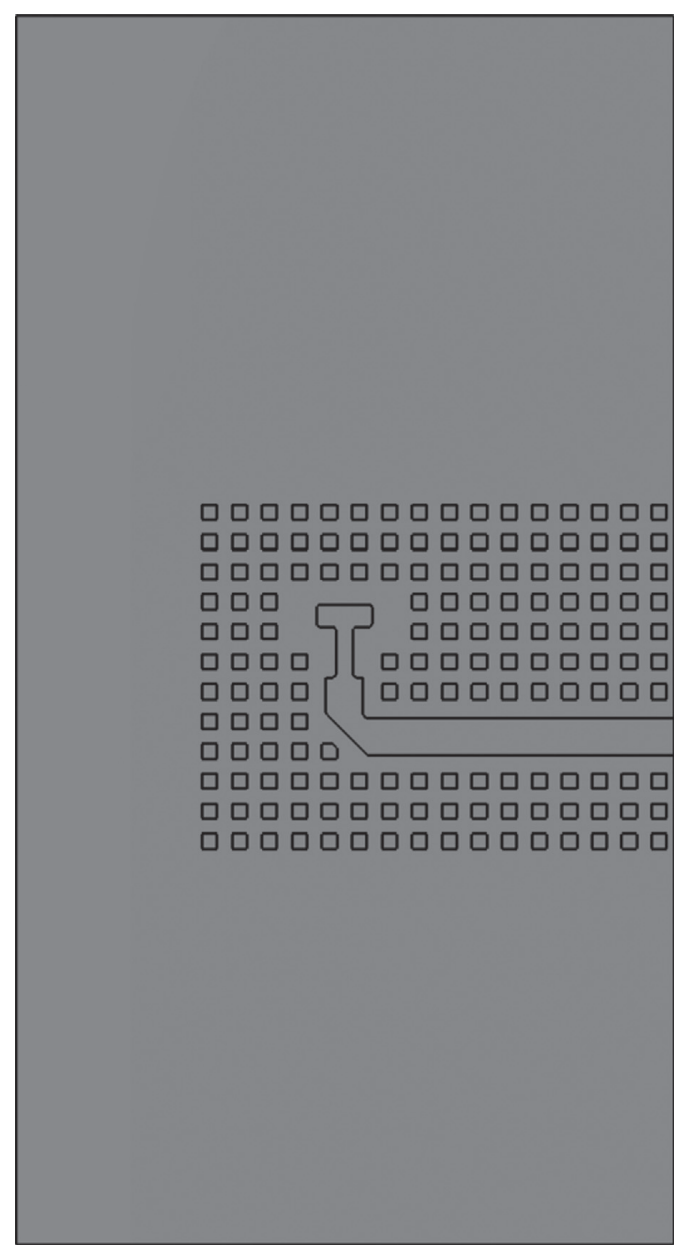

(a)

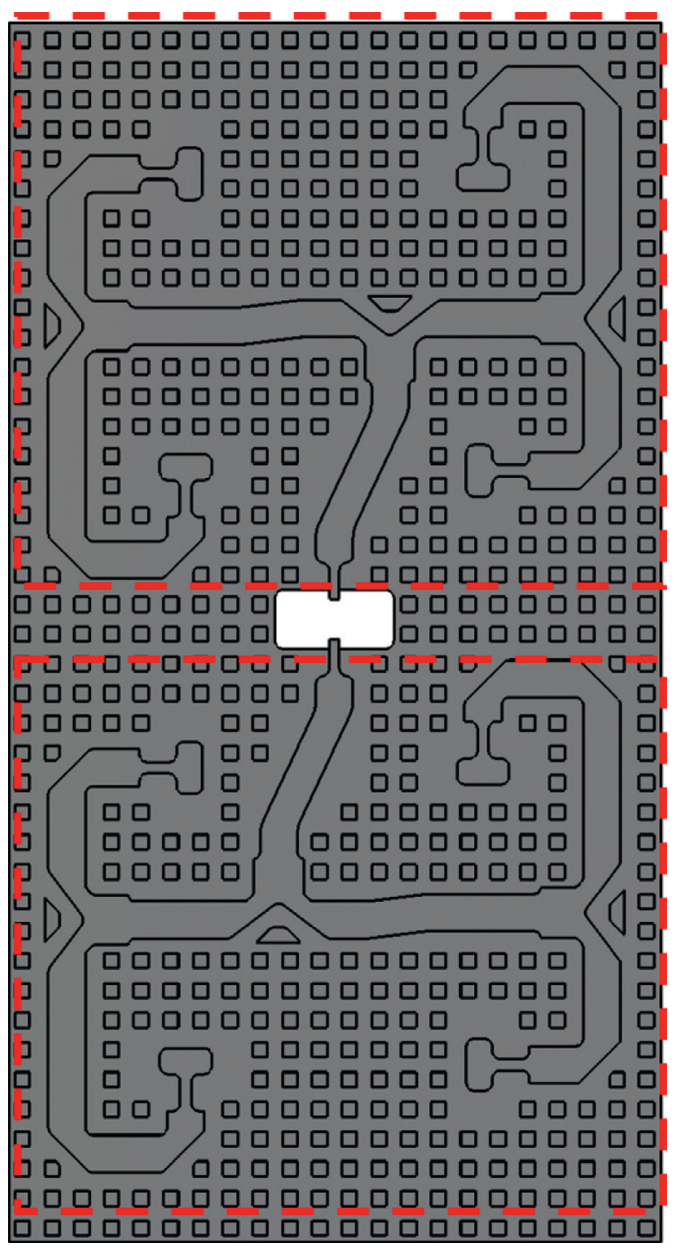

(b)

Figure 9: Feeding network layers of a $4 \times 8$ array. (a) Feed-2. (b) Feed-1.

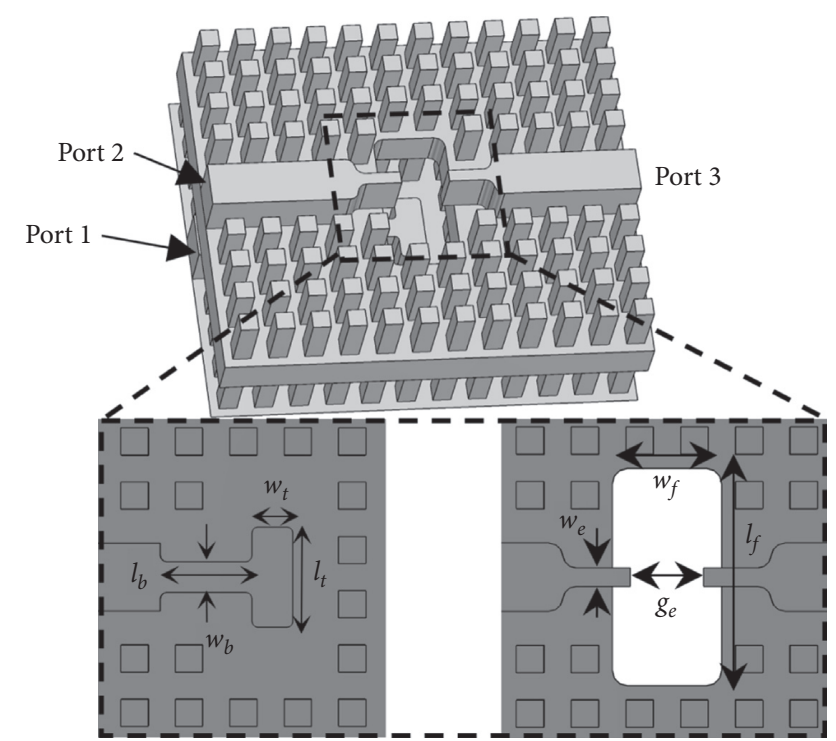

Figure 10: The structure of the $E$-probe transition between feed-1 and feed-2 layers $\left(l_{f}=7 \mathrm{~mm}, w_{f}=3.45 \mathrm{~mm}, w_{e}=0.6 \mathrm{~mm}\right.$, $g_{e}=2.38 \mathrm{~mm}, \quad l_{t}=3.28 \mathrm{~mm}, \quad w_{t}=1.34 \mathrm{~mm}, \quad l_{b}=3 \mathrm{~mm}, \quad$ and $\left.w_{b}=1 \mathrm{~mm}\right)$.

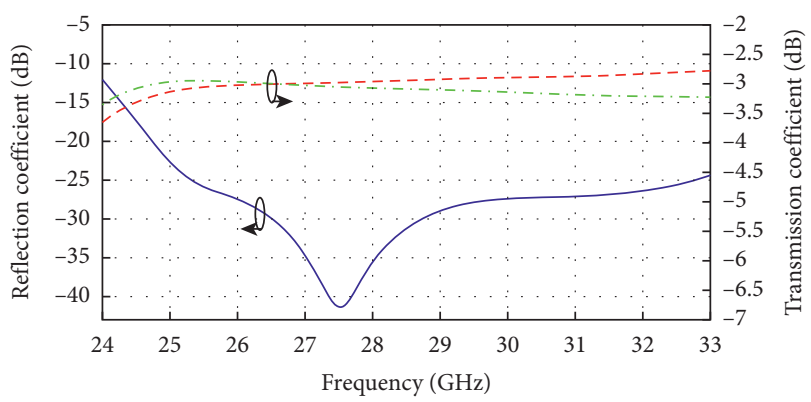

FIGURE 11: The simulated reflection and transmission coefficient of the E-probe transition between feed-1 and feed- 2 .

outputs have $180^{\circ}$ phase difference. Therefore, this phase difference and the phase difference caused by the rotation of the sequential feeding network are canceled with each other, and two 4-way sequential-phase feeding networks are excited in the same phase and amplitude. The expanded feeding network for a $16 \times 16$ array antenna is shown in Figure 8. In the bottom layer (feed-2), a feeding network with 8 outputs is designed. This feeding network consists of $7 \mathrm{~T}$-junction power dividers and excites 


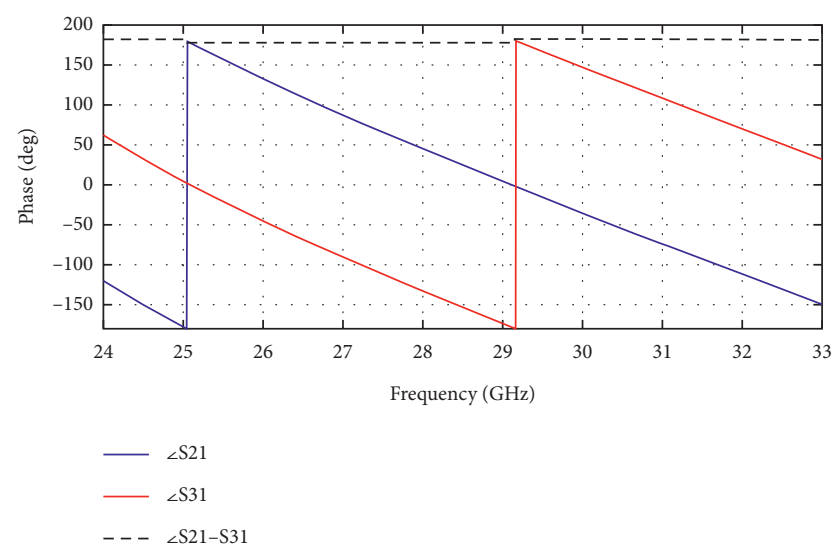

FIGURE 12: Simulated output phases of the E-probe transition between feed-1 and feed-2.

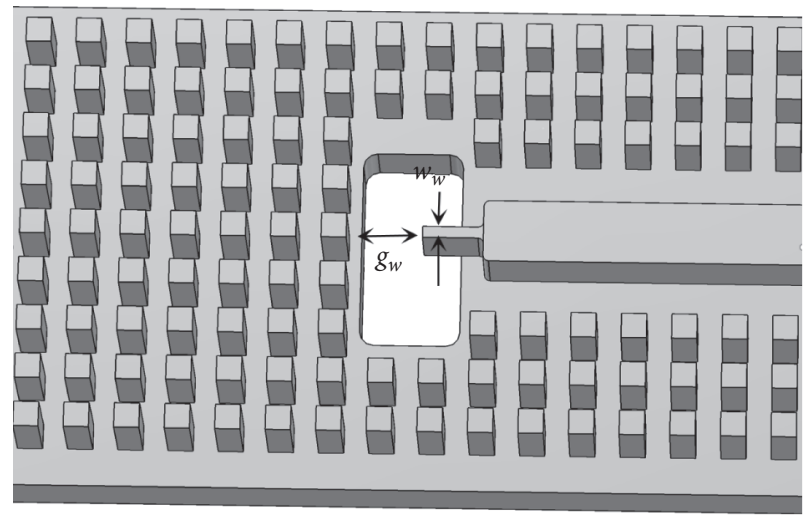

FIgURE 13: Geometry of the rectangular waveguide to ridge gap waveguide transition $\left(w_{p}=0.4 \mathrm{~mm}\right.$ and $\left.g_{p}=2.23 \mathrm{~mm}\right)$.

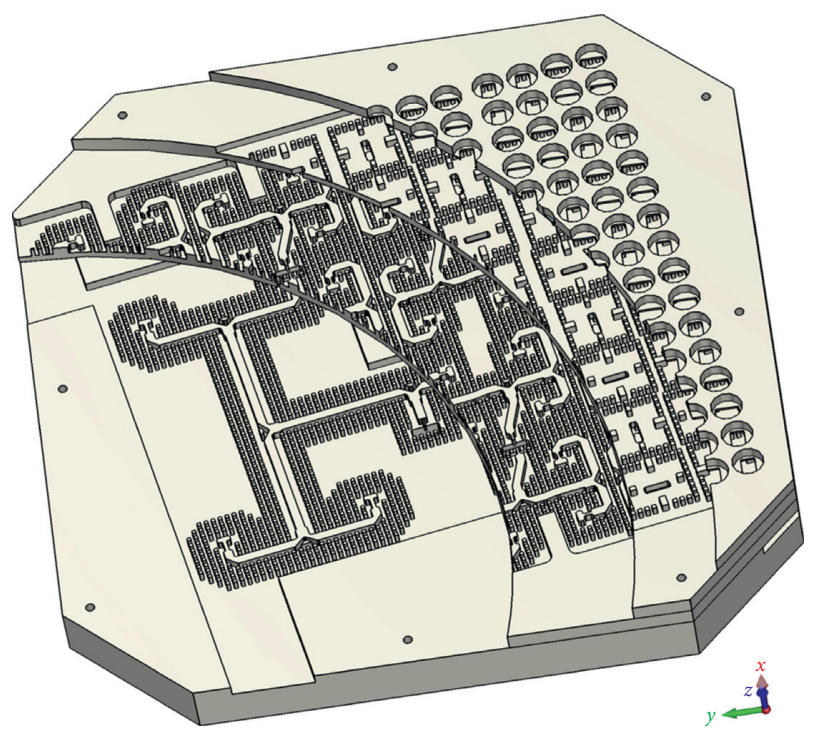

FIGURE 14: The perspective view of the simulated $16 \times 16 \mathrm{CP}$ array antenna.

all coupling slots in the feed-2 layer with the same phase and amplitude. An E-probe transition is utilized to match the $\mathrm{TE}_{10}$ mode of the WR-28 rectangular

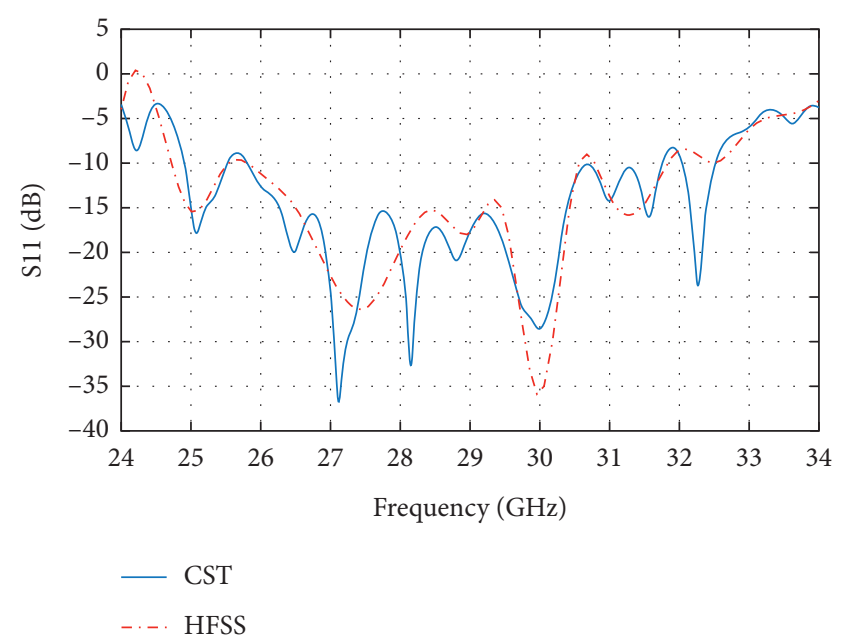

FIGURE 15: Simulated reflection coefficient of the $16 \times 16 \mathrm{CP}$ array antenna.

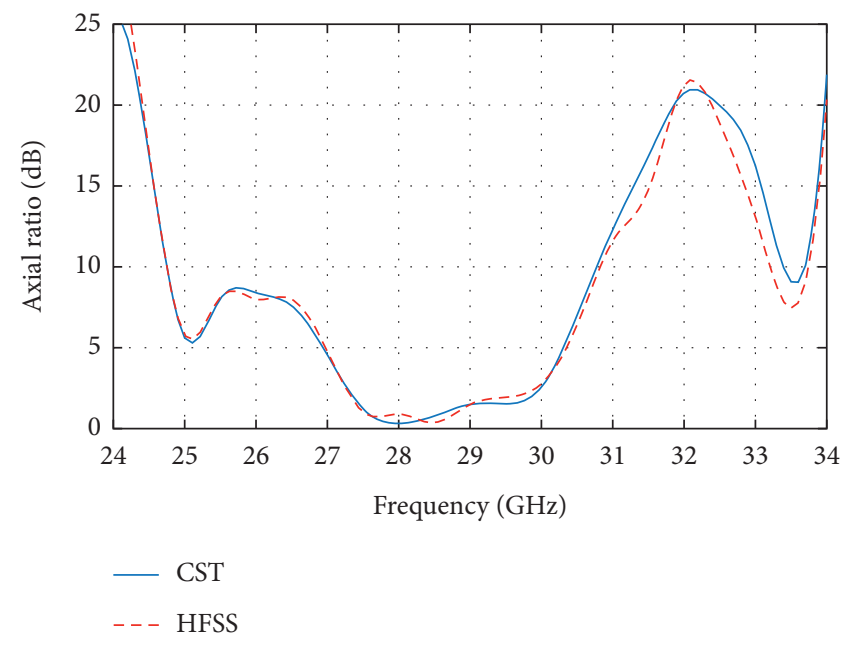

FIGURE 16: Simulated axial ratio of the $16 \times 16 \mathrm{CP}$ array antenna.

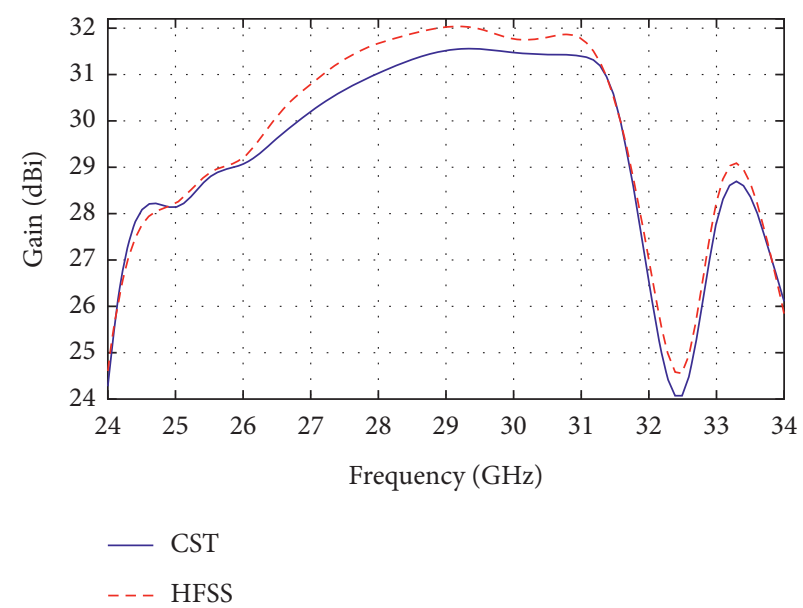

FIGURE 17: Simulated gain of the $16 \times 16 \mathrm{CP}$ array antenna. 


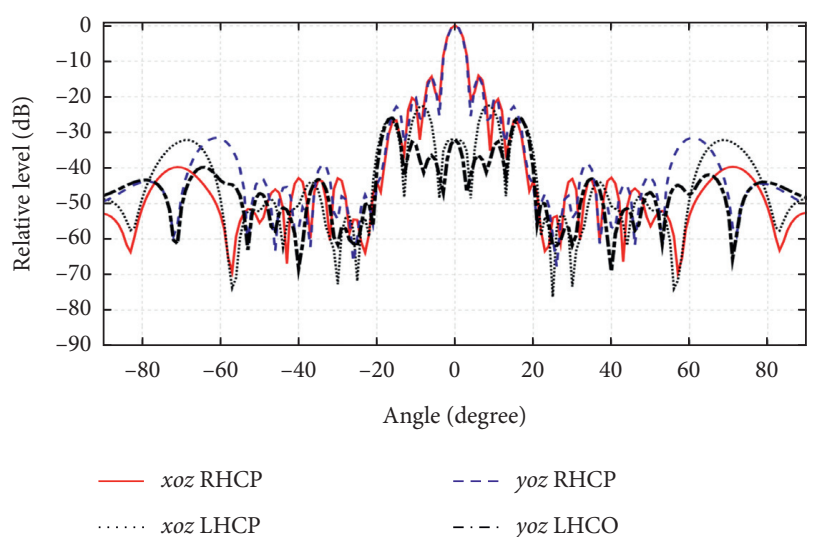

(a)

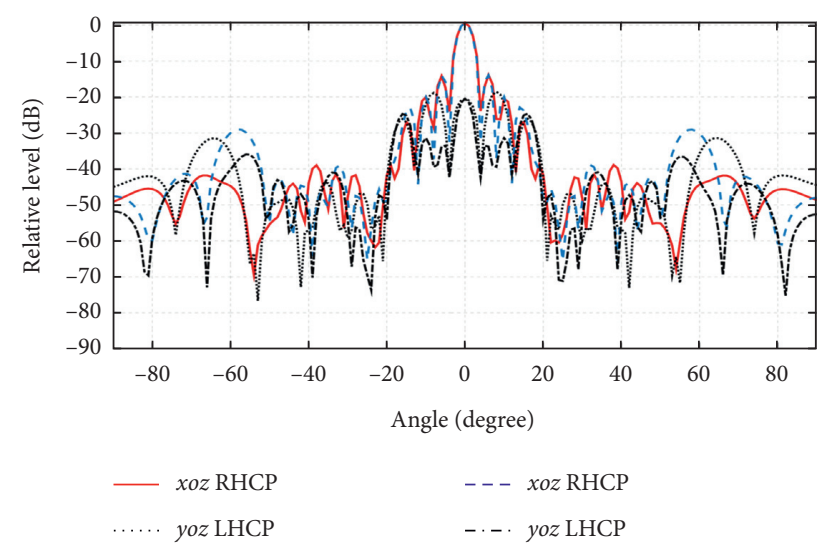

(b)

FIGURE 18: Simulated normalized radiation patterns of the antenna array at (a) $28 \mathrm{GHz}$ and (b) $29 \mathrm{GHz}$.

TABLE 2: Comparison between proposed and reported millimeter-wave CP array antennas.

\begin{tabular}{lcccccc}
\hline $\begin{array}{l}\text { Year/ } \\
\text { reference }\end{array}$ & $f_{0}(\mathrm{GHz})$ & Impedance B. W. (\%) & AR B. W. (\%) & Max. gain (dBi) & Number of radiation elements & Feeding technology \\
\hline $2016 /[4]$ & 20 & 15.9 & 13.8 & 25.9 & 64 & SIW \\
$2014 /[46]$ & 22.7 & 25.5 & 17.9 & 18.7 & 64 & SIW \\
$2016 /[47]$ & 28.3 & 28.5 & 14 & 18.2 & 256 & Stripline \\
$2017 /[48]$ & 30 & 16 & 16 & 32.8 & 64 & CPW \\
$2018 /[22]$ & 30 & 5 & 6 & 22 & 200 & RGW \\
$2019 /[20]$ & 31 & 22 & 8.45 & 31.5 & 256 & RGW \\
$2021 /[34]$ & 35 & 8.45 & 10 & 31.6 & & RGW \\
This paper & 28 & 20.5 & & & RGW \\
\hline
\end{tabular}

waveguide to the quasi-TEM mode of the ridge gap waveguide. The geometry of the proposed transition is shown in Figure 13.

Figure 14 shows the perspective view of the simulated $16 \times 16 \mathrm{CP}$ array antenna simulated with CST and HFSS software to compare results. The simulated reflection coefficient of the array is illustrated in Figure 15. The result shows that the simulated results of CST and HFSS are in quite good agreement, and the impedance bandwidth is $20 \%$ from 25.8 to $31.7 \mathrm{GHz}$. As shown in Figure 16, the simulated $3 \mathrm{~dB}$ AR bandwidth is $10 \%$ from 27.2 to $30 \mathrm{GHz}$. The simulated gain of the array antenna is plotted in Figure 17. According to this figure, the gain is above $28 \mathrm{dBi}$ from 24.5 to $31.9 \mathrm{GHz}$. The maximum gain value is $31.6 \mathrm{dBi}$ which occurred at $29 \mathrm{GHz}$.

Figure 18 shows the simulated normalized LHCP and RHCP radiation pattern of the antenna in two orthogonal planes at 28 and $29 \mathrm{GHz}$. The maximum sidelobe level of the antenna is about $-13.9 \mathrm{~dB}$, and the cross-polarization level is below $-34 \mathrm{~dB}$. Table 2 presents the results of several planar $\mathrm{CP}$ array antennas for comparison. The proposed antenna has good impedance bandwidth and maximum gain comparable to other antennas with different feeding mechanisms. However, the AR bandwidth has decreased compared to the common RGW-based antenna in [20], which has a two-level sequential feeding network, while the feeding network of the proposed antenna has one sequential-phase rotation level.

\section{Conclusion}

In this paper, a wideband and high-gain RHCP array antenna has been presented. The CP array uses a linear polarized $2 \times 2$ subarray based on GGW technology and employs the sequential rotation RGW feeding network. In addition, the $4 \times 4 \mathrm{CP}$ array is expanded to a $16 \times 16$ array antenna. The simulated results show that the impedance bandwidth and $3 \mathrm{~dB}$ AR bandwidth are $20 \%$ and $10 \%$, respectively, with maximum gain.

\section{Data Availability}

The CST and HFSS simulation data used to support the findings of this study are available from the corresponding author upon request.

\section{Conflicts of Interest}

The authors declare that they have no conflicts of interest.

\section{References}

[1] Y. Li and K.-M. Luk, “60-GHz substrate integrated waveguide fed cavity-backed aperture-coupled microstrip patch antenna arrays," IEEE Transactions on Antennas and Propagation, vol. 63, no. 3, pp. 1075-1085, 2015.

[2] L. Wang, Y. J. Cheng, D. Ma, and C. X. Weng, "Wideband and dual-band high-gain substrate integrated antenna array for 
$E$-band multi-gigahertz capacity wireless communication systems," IEEE Transactions on Antennas and Propagation, vol. 62, no. 9, pp. 4602-4611, 2014.

[3] S. B. Yeap, Z. N. Chen, and X. Qing, "Gain-enhanced 60-GHz LTCC antenna array with open air cavities," IEEE Transactions on Antennas and Propagation, vol. 59, no. 9, pp. 3470-3473, 2011.

[4] D.-F. Guan, C. Ding, Z.-P. Qian, Y.-S. Zhang, Y. Jay Guo, and K. Gong, "Broadband high-gain SIW cavity-backed circularpolarized array antenna," IEEE Transactions on Antennas and Propagation, vol. 64, no. 4, pp. 1493-1497, 2016.

[5] D.-F. Guan, C. Ding, Z.-P. Qian, Y.-S. Zhang, W.-Q. Cao, and E. Dutkiewicz, "An SIW-based large-scale corporate-feed array antenna," IEEE Transactions on Antennas and Propagation, vol. 63, no. 7, pp. 2969-2976, 2015.

[6] M. Mohammadi Shirkolaei, "Wideband linear microstrip array antenna with high efficiency and low side lobe level," International Journal of $R F$ and Microwave Computer-Aided Engineering, vol. 30, no. 11, p. e22412, 2020.

[7] N. Hussain, M.-J. Jeong, A. Abbas, and N. Kim, "Metasurfacebased single-layer wideband circularly polarized MIMO antenna for $5 \mathrm{G}$ millimeter-wave systems," IEEE Access, vol. 8, pp. 130293-130304, 2020.

[8] Y. Miura, J. Hirokawa, M. Ando, Y. Shibuya, and G. Yoshida, "Double-layer full-corporate-feed hollow-waveguide slot array antenna in the $60-\mathrm{GHz}$ band," IEEE Transactions on Antennas and Propagation, vol. 59, no. 8, pp. 2844-2851, 2011.

[9] P. Liu, J. Liu, W. Hu, and X. Chen, "Hollow waveguide $32 \times 32$-slot array antenna covering $71-86 \mathrm{GHz}$ band by the technology of a polyetherimide fabrication," IEEE Antennas and Wireless Propagation Letters, vol. 17, no. 9, pp. 1635-1638, 2018.

[10] S.-G. Zhou, G.-L. Huang, T.-H. Chio, J.-J. Yang, and G. Wei, "Design of a wideband dual-polarization full-corporate waveguide feed antenna array," IEEE Transactions on Antennas and Propagation, vol. 63, no. 11, pp. 4775-4782, 2015.

[11] G.-L. Huang, S.-G. Zhou, T.-H. Chio, H.-T. Hui, and T.-S. Yeo, "A low profile and low sidelobe wideband slot antenna array feb by an amplitude-tapering waveguide feednetwork," IEEE Transactions on Antennas and Propagation, vol. 63, no. 1, pp. 419-423, 2015.

[12] M. Zhang, J. Hirokawa, and M. Ando, "An E-band partially corporate feed uniform slot array with laminated quasi double-layer waveguide and virtual PMC terminations," IEEE Transactions on Antennas and Propagation, vol. 59, no. 5, pp. 1521-1527, 2011.

[13] A. Zaidi, B. Abdennaceur, W. Awan, S. Faleh, A. Ballouk, and A. Badri, "Analysis and optimisation of $8 \times 1$ double " $U$ " slotted patch array for future $5 \mathrm{G}$ communications," International Journal of Systems, Control and Communications, vol. 11, p. 305, 2020.

[14] M. Alibakhshikenari, B. S. Virdee, C. H. See, R. AbdAlhameed, F. Falcone, and E. Limiti, "A new waveguide slot array antenna with high isolation and high antenna bandwidth operation on $K U$ - and $K$-bands for radar and MIMO systems," in Proceedings of the 2018 15th European Radar Conference (EuRAD), pp. 401-404, Madrid, Spain, September 2018.

[15] M. Mohammadi Shirkolaei, "High efficiency X-band seriesfed microstrip array antenna," Progress in Electromagnetics Research C, vol. 105, pp. 35-45, 2020.

[16] J. Wu, Y. J. Cheng, and Y. Fan, "A wideband high-gain highefficiency hybrid integrated plate array antenna for $V$-band inter-satellite links," IEEE Transactions on Antennas and Propagation, vol. 63, no. 4, pp. 1225-1233, 2015.

[17] B. Cao, H. Wang, Y. Huang, and J. Zheng, "High-gain L-probe excited substrate integrated cavity antenna array with LTCCbased gap waveguide feeding network for $W$-band Application," IEEE Transactions on Antennas and Propagation, vol. 63, no. 12, pp. 5465-5474, 2015.

[18] P.-S. Kildal, E. Alfonso, A. Valero-Nogueira, and E. RajoIglesias, "Local metamaterial-based waveguides in gaps between parallel metal plates," IEEE Antennas and Wireless Propagation Letters, vol. 8, pp. 84-87, 2009.

[19] P.-S. Kildal, "Artificially soft and hard surfaces in electromagnetics," IEEE Transactions on Antennas and Propagation, vol. 38, no. 10, pp. 1537-1544, 1990.

[20] M. Akbari, A. Farahbakhsh, and A.-R. Sebak, "Ridge gap waveguide multilevel sequential feeding network for highgain circularly polarized array antenna," IEEE Transactions on Antennas and Propagation, vol. 67, no. 1, pp. 251-259, 2019.

[21] A. Vosoogh, M. S. Sorkherizi, A. U. Zaman, J. Yang, and A. A. Kishk, "An integrated $\mathrm{Ka}$-band diplexer-antenna array module based on gap waveguide technology with simple mechanical assembly and no electrical contact requirements," IEEE Transactions on Microwave Theory and Techniques, vol. 66, no. 2, pp. 962-972, 2018.

[22] M. Ferrando-Rocher, J. I. Herranz-Herruzo, A. ValeroNogueira, and A. Vila-Jiménez, "Single-layer circularly-polarized $\mathrm{Ka}$-band antenna using gap waveguide technology," IEEE Transactions on Antennas and Propagation, vol. 66, no. 8, pp. 3837-3845, 2018.

[23] A. Farahbakhsh, D. Zarifi, and A. U. Zaman, "A mmWave wideband slot array antenna based on ridge gap waveguide with 30\% bandwidth," IEEE Transactions on Antennas and Propagation, vol. 66, no. 2, pp. 1008-1013, 2018.

[24] A. Vosoogh, P.-S. Kildal, and V. Vassilev, "Wideband and high-gain corporate-fed gap waveguide slot array antenna with ETSI class II radiation pattern in $V$-band," IEEE Transactions on Antennas and Propagation, vol. 65, no. 4, pp. 1823-1831, 2017.

[25] J. Liu, A. Vosoogh, A. U. Zaman, and J. Yang, "Design and fabrication of a high-gain $60-\mathrm{GHz}$ cavity-backed slot antenna array fed by inverted microstrip gap waveguide," IEEE Transactions on Antennas and Propagation, vol. 65, no. 4, pp. 2117-2122, 2017.

[26] A. Farahbakhsh, D. Zarifi, and A. U. Zaman, "60-GHz groove gap waveguide based wideband $H$-plane power dividers and transitions: for use in high-gain slot array antenna," IEEE Transactions on Microwave Theory and Techniques, vol. 65, no. 11, pp. 4111-4121, 2017.

[27] D. Zarifi, A. Farahbakhsh, A. U. Zaman, and P.-S. Kildal, "Design and fabrication of a high-gain $60-\mathrm{GHz}$ corrugated slot antenna array with ridge gap waveguide distribution layer," IEEE Transactions on Antennas and Propagation, vol. 64, no. 7, pp. 2905-2913, 2016.

[28] A. Vosoogh and P.-S. Kildal, "Corporate-fed planar 60-GHz slot array made of three unconnected metal layers using AMC pin surface for the gap waveguide," IEEE Antennas and Wireless Propagation Letters, vol. 15, pp. 1935-1938, 2016.

[29] A. A. Brazález, E. Rajo-Iglesias, J. L. Vázquez-Roy, A. Vosoogh, and P.-S. Kildal, "Design and validation of microstrip gap waveguides and their transitions to rectangular waveguide, for millimeter-wave applications," IEEE Transactions on Microwave Theory and Techniques, vol. 63, no. 12, pp. 4035-4050, 2015. 
[30] A. Polemi, S. Maci, and P.-S. Kildal, "Dispersion characteristics of a metamaterial-based parallel-plate ridge gap waveguide realized by bed of nails," IEEE Transactions on Antennas and Propagation, vol. 59, no. 3, pp. 904-913, 2011.

[31] P.-S. Kildal, A. U. Zaman, E. Rajo-Iglesias, E. Alfonso, and A. Valero-Nogueira, "Design and experimental verification of ridge gap waveguide in bed of nails for parallel-plate mode suppression," IET Microwaves, Antennas \& Propagation, vol. 5, no. 3, pp. 262-270, 2011.

[32] E. Rajo-Iglesias and P. Kildal, "Groove gap waveguide: a rectangular waveguide between contactless metal plates enabled by parallel-plate cut-off," in Proceedings of the Fourth European Conference on Antennas and Propagation, pp. 1-4, Barcelona, Spain, April 2010.

[33] A. A. Brazalez, A. U. Zaman, and P.-S. Kildal, "Improved microstrip filters using PMC packaging by lid of nails," IEEE Transactions on Components, Packaging and Manufacturing Technology, vol. 2, no. 7, pp. 1075-1084, 2012.

[34] L. Kong, C. Jin, H. Han, J. Chen, J. Li, and J. Liu, "A righthanded circularly polarized array antenna based on gap waveguide technology at $35 \mathrm{GHz}$," Microwave and Optical Technology Letters, vol. 63, no. 7, pp. 1955-1959, 2021.

[35] C. Deng, Y. Li, Z. Zhang, and Z. Feng, "A wideband sequential-phase fed circularly polarized patch array," IEEE Transactions on Antennas and Propagation, vol. 62, no. 7, pp. 3890-3893, 2014.

[36] H. Sun, Y.-X. Guo, and Z. Wang, "60-GHz circularly polarized $U$-slot patch antenna array on LTCC," IEEE Transactions on Antennas and Propagation, vol. 61, no. 1, pp. 430-435, 2013.

[37] W. Zhou, J. Liu, and Y. Long, "A broadband and high-gain planar complementary yagi array antenna with circular polarization," IEEE Transactions on Antennas and Propagation, vol. 65, no. 3, pp. 1446-1451, 2017.

[38] Y. Li and K.-M. Luk, "A 60-GHz wideband circularly polarized aperture-coupled magneto-electric dipole antenna array," IEEE Transactions on Antennas and Propagation, vol. 64, no. 4, pp. 1325-1333, 2016.

[39] Y. Li, Z. N. Chen, X. Qing, Z. Zhang, J. Xu, and Z. Feng, “Axial ratio bandwidth enhancement of $60-\mathrm{GHz}$ substrate integrated waveguide-fed circularly polarized LTCC antenna array," IEEE Transactions on Antennas and Propagation, vol. 60, no. 10, pp. 4619-4626, 2012.

[40] N. Hussain, M.-J. Jeong, J. Park, and N. Kim, "A broadband circularly polarized fabry-perot resonant antenna using a single-layered PRS for 5 G MIMO applications," IEEE Access, vol. 7, pp. 42897-42907, 2019.

[41] M. M. Shirkolaei and M. Jafari, "A new class of wideband microstrip falcate patch antennas with reconfigurable capability at circular-polarization," Microwave and Optical Technology Letters, vol. 62, no. 12, pp. 3922-3927, 2020.

[42] K. D. Palmer, J. H. Cloete, and J. J. v. Tonder, "Bandwidth improvement of circularly polarised arrays using sequential rotation," in Proceedings of the IEEE Antennas and Propagation Society International Symposium 1992 Digest, pp. 135-138, Chicago, IL, USA, June 1992.

[43] L. Ko Han and C. The-Nan, "Circularly polarized array antenna with corporate-feed network and series-feed elements," IEEE Transactions on Antennas and Propagation, vol. 53, no. 10, pp. 3288-3292, 2005.

[44] C. Deng, Y. Li, Z. Zhang, and Z. Feng, "A circularly polarized pattern diversity antenna for hemispherical coverage," IEEE Transactions on Antennas and Propagation, vol. 62, no. 10, pp. 5365-5369, 2014.
[45] Y. Lu, D.-G. Fang, and H. Wang, "A wideband circularly polarized $2 \times 2$ sequentially rotated patch antenna array," Microwave and Optical Technology Letters, vol. 49, pp. 1405-1407, 2007.

[46] Y. Lang, S. Qu, and J. Chen, "Wideband circularly polarized substrate integrated cavity-backed antenna array," IEEE Antennas and Wireless Propagation Letters, vol. 13, pp. 1513-1516, 2014.

[47] J. Wu, Y. J. Cheng, and Y. Fan, "Millimeter-wave wideband high-efficiency circularly polarized planar array antenna," IEEE Transactions on Antennas and Propagation, vol. 64, no. 2, pp. 535-542, 2016.

[48] J. Wu, Y. J. Cheng, H. B. Wang, Y. C. Zhong, D. Ma, and Y. Fan, "A wideband dual circularly polarized full-corporate waveguide array antenna fed by triple-resonant cavities," IEEE Transactions on Antennas and Propagation, vol. 65, no. 4, pp. 2135-2139, 2017. 